\title{
Idiopathic Scrotal Oedema
}

\section{Case Report and Literature Review}

\author{
Maj D W J McCreadie \\ MB, ChB, RAMC \\ Princess Alexandra Hospital, RAF Wroughton
}

SUMMARY: A case of idiopathic scrotal oedema is presented in detail and the aetiology, diagnosis and treatment considered with reference to the literature available.

\section{Case Report}

A five year old boy was admitted to hospital with a 12 hour history of mild pain in his right scrotum associated with slowly increasing swelling. There were no bowel or urinary symptoms. He had no systemic upset, history of injury or known allergies.

Examination revealed an apyrexial boy who did not look ill. His right scrotum was grossly swollen and indurated, the oedema radiating upwards over the right inguinal ligament and downwards into the perineum. The scrotum transilluminated. Pitting of the oedematous areas could not be demonstrated. There were no bowel or urinary symptoms. He had $1 \mathrm{~cm}$ in diameter, at the neck of the scrotum. Due to the swelling the testis was difficult to delineate and the spermatic cord was impalpable. Examination of the rest of the abdomen revealed no clinical abnormality, in particular there was no inguinal lymphadenopathy and anal inspection was normal. Neither proctoscopy nor PR examination was performed.

The working diagnosis was either testicular torsion or epididymitis and in view of the possible sequelae of the former the patient was submitted to surgical exploration.

The operation, performed through an inguinal incision, revealed grossly oedematous skin and subcutaneous tissues. The testis, cord and epididymis were normal and no hydrocele was found. In view of these findings no further procedure was undertaken.

Twelve hours after operation the scrotal and perineal oedema had increased and spread to the left scrotum and the right lower abdominal wall. At the same time the patient developed a pyrexia of $38.0^{\circ} \mathrm{C}$ orally but there was no evidence of wound infection. The patient was kept under observation with no further active treatment and 36 hours after admission the oedema and pyrexia had settled. The patient was discharged the following day. $48 \mathrm{hrs}$ after admission. Outpatient review, six days later, revealed a well healed wound, normal scrotum and contents, no evidence of skin lesions and no histor of post-operative complications at home. A retro spective diagnosis of idiopathic scrotal oedema was 9 made.

\section{Discussion}

Idiopathic scrotal oedema is described in one of the leading textbooks of surgery as severe swellin of the scrotum which may extend to the perineung or groin but is not associated with the exquisite tenderness of torsion and pain is slight ${ }^{1}$. It usualls subsides in 1 or 2 days.

The condition is not common and most published series discuss numbers between six and $30^{2,3,4}$. A variety of causes has been suggested including anal gland or crypt inflammation 5 , localised angioneurotic oedema or allergy ${ }^{3}$ and local cellulitis, possibly spreading from anal fissures". In the reported case local cellulitis was considered the most likely pathology as there was a localised tender erythematous area at the neck of the scrotum, but it should be noted that there was no initial pyrexia, no skin lesion was discovered and healing occurred rapidly without recourse to antibiotics. The epicentre of oedema appeared to be the scrotal neck thereby tending to exclude anal gland inflammation as a source of infection as does the fact that there were no bowel symptoms although Nicholas ${ }^{4}$ reports only one out of six perianal lesions causing bowel symptoms. Allergies of various types seem unlikely considering the asymmetry of presenting signs and the lack of any other allergic manifestations".

The short course of the condition, full resolution within three days whether treated actively or not, is emphasized throughout the literature ${ }^{1,4,6}$. The only complications reported are recurrences, often years 2 
later, and occasional wound breakdown following surgery ${ }^{1,4}$. It is difficult to support recommendations for routine antibiotic therapy as advocated by Nicholas $^{1}$ when there is no report of untreated idiopathic scrotal oedema failing to resolve.

The importance of the lesion is that it must be differentiated from torsion of the testis, torsion of the appendix of the testis, incarcerated hernia and epididymo-orchitis $s^{4, "}$. In idiopathic scrotal oedema the oedema usually starts unilaterally and is extensive, there is only mild pain and tenderness and, if palpable, the testis and cord feel normal. The incidence of torsion and idiopathic scrotal oedema in infants and children is similar ${ }^{4,6}$ but once in their tcens idiopathic scrotal oedema is very rare.

\section{Conclusion}

Although Nicholas ${ }^{4}$ advocates wider recognition of this lesion most references appear in the specialised journals ${ }^{1,2,3}$. The aetiology is still obscure but the current label is useful because it emphasizes the clinical appearance of the lesion, where it occurs and most importantly that the cause is unknown and therefore surgery is not likely to be of benefit. With wider recognition such patients are less likely to proceed to surgical exploration with all the inherent risks but if doubt still exists then surgery is the safer and more correct approach.

\section{Acknowledgements}

I wish to thank Mr I Joffe who encouraged m® to write this report about his patient and Colonel Johnston who helped with the preparation of the 즐 ariicle. My thanks to Mrs Hughes for typing the. manuscript.

REFERENCES
1 BAILEY \& Love's. Short Practice of Surgery
Ed H K Lewis \& Co Ltd. 1981; 1321.
2 KAPLAN G W. Acute idiopathic scrotal oedem? $J$ Pediatr Surg 1977; 12(5): 647-9.

3 Evans $\mathbf{J} \mathbf{P}$ and SNyder $\mathbf{H} \mathbf{M}$. Idiopathic szrotal oedema. Urology 1977; 9(5): 539-51.

4. Nicholas J L, Morgan A and Zachery R B. Ifró pathic oedema of scrotum in young boys. Surg $1970 ; 67(5): 847-50$.

5 Terpstra $O$ T and Molenaar J C. An explanatipar of idiopathic scrotal oedema in boys. Ned Tijdsell Geneeskd 1978; 122(4): 112-4.

6 QuisT $\mathbf{O}$. Swelling of the scrotum in infants children, and non specific epididymitis. Study 158 cases. Acta Chir Scand 1956; 110: 417.

\section{Tax Relief-Subscription to the Journal of the Royal Army Medical Corps}

Under Section 192 Income and Corporation Taxes Act 1970 the whole of the annual subscription to the Journal of the RAMC paid by a member who qualifies for relief under that Section is allowable (wef 6 April 1981) as a deduction from his emolu- ments assessable to Income Tax under Schedule

A member who is entitled to the relief should apply to his Tax Office giving details of his sube scription and making a claim for the relief due t him. 